\title{
Nutrition, Mental Status and Level of 8-hydroxy- 2-deoxyguanosine (OHdG) Urine as Predictors of Premenstrual Syndrome (PMS) in Adolescent Girls
}

\author{
Julian Purnawati ${ }^{1}$, Andi Wardihan Sinrang ${ }^{1}$, Elizabet Catherine Jusuf ${ }^{2}$, \\ Erlyn Limoa ${ }^{3}$, Mardiana Ahmad ${ }^{1}$, Andi Nilawati Usman'
}

'Department of Midwifery, Graduate School, Hasanuddin University, Indonesia; 'Department of Obstetrics and Gynecology, Faculty of

Medicine, Hasanuddin University, Indonesia; ${ }^{2}$ Department of Psychiatry, Faculty of Medicine, Hasanuddin University, Indonesia.

\section{ABSTRACT}

Objective: This study was aimed to determine the prevalence of PMS, the relationship of nutritional intake, mental status, and levels of 8-OHdG in urine with PMS events and to find a predictor model of PMS events.

Methods: Observational analytic study design case-control study and cross-sectional study (hybrid method), samples of 90 students class X and XI at SMAN 21 Makassar was conducted in February-March 2020. Data included 2x24 hour food recall, food frequency questionnaire, stress, depression and anxiety scores, and 8-OHdG levels in girls' urine. Data analysis using chisquare test, receiver operating characteristic curve analysis, and logistic regression.

Results: The prevalence of PMS was $28.9 \%$. There was a significant correlation between fat intake, calcium, zinc, stress, depression, and urine 8-OHdG levels with the incidence of PMS $(p<0.05$ and $p<0.01)$. Stress and $8-O H d G$ levels in urine as a predictor of PMS events $(p<0.01 ; R 2=0.208)$.

Conclusion: Stress and 8-OHdG levels in urine can be a predictor of PMS events.

Key Words: Nutrition, Mental Status, 8-hydroxy-2-deoxyguanosine, Premenstrual syndrome

\section{INTRODUCTION}

PMS is a series of symptoms in the form of physical and emotional disturbance or discomfort in women 1-2 weeks before menstruation (luteal phase). ${ }^{1,2}$ The prevalence of PMS is $37.5 \%$ in Saudi Arabia, $17.5 \%$ in Japan, $41 \%$ in America, 43.2-52.2\% in Brazil, $10-12 \%$ in women in Europe and the highest rate of $98 \%$ occurs in Asian women. ${ }^{1}$ PMS impacts social relationships, work, academic achievement. This also has an impact on the economy, which is increasing absenteeism, reducing academic efficiency and student achievement, incurring additional costs for health care, thereby reducing the quality of life. ${ }^{1-3}$. PMS also affects the occurrence of prenatal depression to postpartum depression. ${ }^{4,5}$

Previous research shows that several factors such as hormonal disorders, genetic, psychological factors, lack of vitamins and minerals, lifestyle (smoking, alcohol consumption, eating habits, and lack of exercise) as well as oxidative stress are associated with the occurrence of PMS. ${ }^{1,2,6,7}$ High carbohydrate, fat and protein intake ${ }^{1,2,8}$, lack of calcium, vitamin, and zinc intake ${ }^{9-11}$, and psychological factors (stress, depression, and anxiety) are thought to play a role in the occurrence of PMS. ${ }^{1,3,12-15}$

Research also shows oxidative stress is higher in women who experience PMS. ${ }^{7}$ 8-OHdG levels are the main biomarkers of oxidative stress and show high stability in urine. ${ }^{16}$ Adolescent girls aged 15-17 as a transition phase from childhood to adulthood with dense activity inside/ outside of school are vulnerable to experiencing PMS. This study was conducted to determine the prevalence of PMS, the relationship of nutritional intake, mental status, and levels of $8-\mathrm{OHdG}$ in urine with the incidence of PMS and determine the predictor models of PMS events in adolescents.

\section{Corresponding Author:}

Andi Wardihan Sinrang, Department of Midwifery, Graduate School, Hasanuddin University, Indonesia. Email: wardihan@pasca.unhas.ac.id

ISSN: 2231-2196 (Print)

Received: 18.07 .2020
ISSN: 0975-5241 (Online)

Revised: 23.09 .2020
Accepted: 07.11 .2020 


\section{MATERIALS AND METHODS}

\section{Research site}

This research was conducted in February-March 2019 at SMAN 21 Makassar. Ethical permission has been obtained by the ethics committee of Medicine Faculty of Hasanuddin University with Recommendation Number 149/ UN.4.6.4.5.31/PP36/2020. All subjects who participated were given information about the study's purpose and aim and asked for informed consent before they participated.

\section{Data Types and Sources}

Data include intake of carbohydrates, protein, fat, calcium, zinc, vitamin D, stress, depression, anxiety, and urine 8-OHdG levels.

\section{Data collection technique}

Using $2 \times 24$ hours food recall questionnaire, food frequency questionnaires (FFQ), Depression Anxiety Stress Scale (DASS) 42. Sampling the urine by the researcher, then stored in the refrigerator at $-20^{\circ} \mathrm{C}$ and examined using $8-\mathrm{OHdG}$ ELISA Kit at Hasanuddin University Medical Research Center (HUM-RC) Laboratory.

\section{Data Analysis}

The collected data were reviewed, double-checked for completeness and accuracy, and corrected before being entered into the spreadsheet. Questionnaires were coded and being analyzed by using STATA 14.2. Descriptive statistics including mean and standard deviation (SD). ROC curve analysis used to determine the cut-off point for 8-OHdG. A Chi-square test was used to examine the relationship among variables. Odds ratio with $95 \%$ confidence interval also used to present the strength of association between risk factors and outcomes. Then, variables with p-values $(<0.25)$ were entered into multiple logistic regression analyses to examine their association as exposure with PMS as outcomes, and also to determine the predictor model of PMS. P-values $<0.05$ were considered statistically significant for all tests.

\section{RESULTS}

Screening 370 students class X and XI with a total of 22 classes to determine the incidence of PMS obtained as many as 107 teenagers experiencing PMS (28.9\%). Data shows that the characteristics of nutrition intake and mental status especially anxiety among the control groups and PMS groups were in the same categories that are excess of protein, enough for carbohydrates and fat, lack of calcium, zinc and vitamin $\mathrm{D}$, and moderate anxiety. Adolescents in PMS group having moderate stress, mild depression, and high levels of urine 8-OHdG while in the control group were mild stress, not depressed, and low levels of 8-OHdG (Table 1).

\section{Table 1: Respondent characteristics}

\begin{tabular}{|c|c|c|c|}
\hline \multirow[t]{2}{*}{ Variables } & \multicolumn{3}{|c|}{$\bar{X} \pm \mathbf{S D}$} \\
\hline & PMS $(\mathrm{N}=45)$ & Not PMS $(\mathrm{N}=45)$ & Total $(\mathrm{N}=\mathbf{9 0})$ \\
\hline Age (years) & $16.02 \pm 0.72$ & $15.86 \pm 0.72$ & $15.94 \pm 0.72$ \\
\hline Menstrual duration (day) & $5.91 \pm 1.08$ & $5.62 \pm 1.23$ & $5 \cdot 76 \pm 1.16$ \\
\hline Menstrual cycle (day) & $29.24 \pm 1.13$ & $29.33 \pm 1.14$ & $29.28 \pm 1.13$ \\
\hline Carbohydrates (grams) & $297.41 \pm 93.27$ & $311.04 \pm 106.25$ & $304.23 \pm 99.64$ \\
\hline Protein (grams) & $89.77 \pm 98.62$ & $75.26 \pm 23.60$ & $82.51 \pm 71.67$ \\
\hline Fat (grams) & $74.27 \pm 38.77$ & $70.34 \pm 26.31$ & $72.30 \pm 33.01$ \\
\hline Calcium(mg) & $383.72 \pm 353.82$ & $588.88 \pm 426.51$ & $486.30 \pm 403.07$ \\
\hline Vitamin D $(\mu \mathrm{g})$ & $6.71 \pm 4.74$ & $7.60 \pm 4.77$ & $7.16 \pm 4.75$ \\
\hline Zinc (mg) & $8.98 \pm 3.52$ & $10.09 \pm 3.32$ & $9.54 \pm 3.45$ \\
\hline Stress (skor) & $21.42 \pm 7.43$ & $16.44 \pm 6.49$ & $18.93 \pm 7.37$ \\
\hline Depression (skor) & $12.48 \pm 4.59$ & $9.93 \pm 5.36$ & $11.21 \pm 5.13$ \\
\hline Anxiety (skor) & $10.40 \pm 3.30$ & $10.40 \pm 2.51$ & $10.40 \pm 2.92$ \\
\hline 8-OHdG (ng/mL) & $17.94 \pm 10.72$ & $9 \cdot 31 \pm 4.39$ & $13.63 \pm 9.22$ \\
\hline
\end{tabular}

ROC (receiver operating characteristic) curve analysis to determine the cut-off point with a yield of $11.49 \mathrm{ng} /$
$\mathrm{mL}$, with sensitivity of $68.89 \%$, and specificity of $71.11 \%$ (Figure 1). 


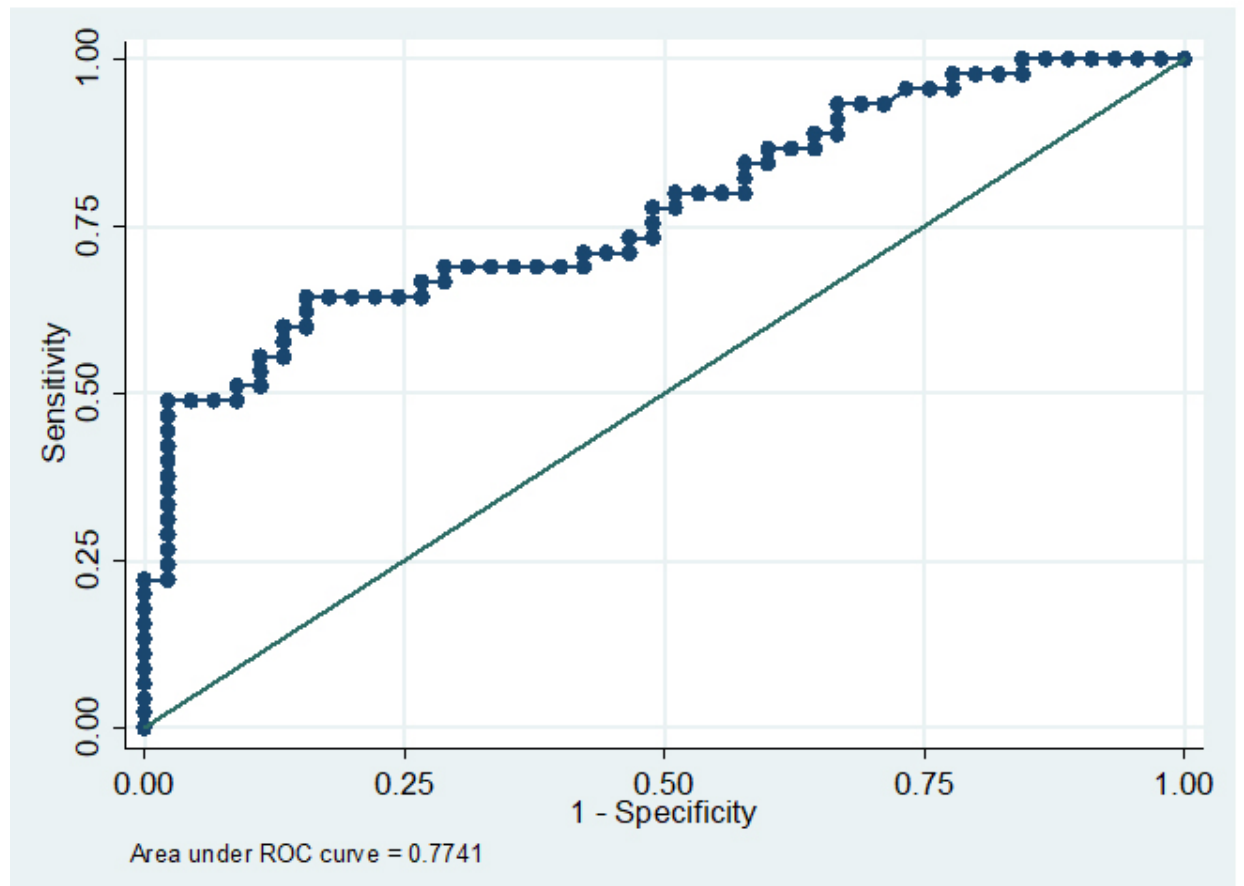

Figure 1: 8-OHdG ROC Curve.

Table 2: Relationship of nutrition intake, mental status and 8-OHdG level in urine with PMS

\begin{tabular}{|c|c|c|c|c|c|c|}
\hline \multirow[t]{2}{*}{ Variables } & \multicolumn{2}{|c|}{ Group } & \multirow[t]{2}{*}{$\mathbf{X}^{2}$} & \multirow[t]{2}{*}{ p-value } & \multirow[t]{2}{*}{ OR } & \multirow[t]{2}{*}{$95 \%$ CI } \\
\hline & $\begin{array}{c}\text { Case (PMS) } \\
\quad(n=45)\end{array}$ & $\begin{array}{c}\text { Control (Not PMS) } \\
(\mathrm{n}=45)\end{array}$ & & & & \\
\hline \multicolumn{7}{|c|}{ Nutrition Intake } \\
\hline \multicolumn{7}{|c|}{ Carbohydrates n (\%) } \\
\hline More & $16(35.56)$ & $21(46.67)$ & 1.28 & 0.525 & 0.5 & $0.21-1.54$ \\
\hline Less & $13(28.89)$ & $12(26.67)$ & & & 0.8 & $0.27-2.40$ \\
\hline Enough & $16(35 \cdot 56)$ & $12(26.67)$ & & & & \\
\hline \multicolumn{7}{|c|}{ Protein n (\%) } \\
\hline More & $24(53.33)$ & $24(53.33)$ & 0.42 & 0.807 & 1.1 & $0.45^{-2.93}$ \\
\hline Less & $8(17.78)$ & $6(13.33)$ & & & 1.5 & $0.42-5.60$ \\
\hline Enough & $13(28.89)$ & $15(33.33)$ & & & & \\
\hline \multicolumn{7}{|l|}{ Fat n (\%) } \\
\hline More & $19(42.22)$ & $14(31.11)$ & 6.72 & 0.035 & $3 \cdot 4$ & $1.14-10.62$ \\
\hline Less & $19(42.22)$ & $13(28.89)$ & & & 3.7 & $1.22-11.54$ \\
\hline Enough & $7(15 \cdot 56)$ & $18(40.00)$ & & & & \\
\hline \multicolumn{7}{|c|}{ Calcium n (\%) } \\
\hline Less & $39(86.67)$ & $30(66.67)$ & 5.03 & 0.025 & 3.2 & $1.12-9 \cdot 37$ \\
\hline Enough & $6(13.33)$ & $15(33.33)$ & & & & \\
\hline \multicolumn{7}{|l|}{ Zinc n (\%) } \\
\hline Less & $35(77 \cdot 78)$ & $25(55.56)$ & 5.00 & 0.025 & 2.8 & $1.11-7.00$ \\
\hline Enough & $10(22.22)$ & $20(44.44)$ & & & & \\
\hline \multicolumn{7}{|c|}{ Vitamin D n (\%) } \\
\hline Less & $38(84.44)$ & $34(75 \cdot 56)$ & 1.11 & 0.292 & 1.7 & $0.61-5.04$ \\
\hline Enough & $7(15.56)$ & $11(24.44)$ & & & & \\
\hline
\end{tabular}


Table 2: (Continued)

\begin{tabular}{|c|c|c|c|c|c|c|}
\hline \multirow[t]{2}{*}{ Variables } & \multicolumn{2}{|c|}{ Group } & \multirow[t]{2}{*}{$\mathrm{X}^{2}$} & \multirow[t]{2}{*}{ p-value } & \multirow[t]{2}{*}{ OR } & \multirow[t]{2}{*}{$95 \% \mathrm{CI}$} \\
\hline & $\begin{array}{c}\text { Case (PMS) } \\
\quad(\mathrm{n}=45)\end{array}$ & $\begin{array}{c}\text { Control (Not PMS) } \\
\qquad(\mathrm{n}=45)\end{array}$ & & & & \\
\hline \multicolumn{7}{|l|}{ Mental Status } \\
\hline \multicolumn{7}{|l|}{ Stress n (\%) } \\
\hline High & $19(42.22)$ & $4(8.89)$ & 17.01 & 0.001 & 10.1 & $2.50-41.38$ \\
\hline Medium & $11(24 \cdot 44)$ & $8(17.78)$ & & & 2.9 & $0.82-10.58$ \\
\hline Low & $8(17.78)$ & $18(40.00)$ & & & 0.9 & $0.28-3.23$ \\
\hline Not experience & $7(15.56)$ & $15(33.33)$ & & & & \\
\hline \multicolumn{7}{|c|}{ Depression n (\%) } \\
\hline Medium & $21(46.67)$ & $14(31.11)$ & 8.15 & 0.017 & $3 \cdot 4$ & $1.26-9.41$ \\
\hline Low & $14(31.11)$ & $8(17.78)$ & & & 4.0 & $1.28-12.6$ \\
\hline Not experience & $10(22.22)$ & $23(51.11)$ & & & & \\
\hline \multicolumn{7}{|l|}{ Anxiety n (\%) } \\
\hline Medium & $32(71.11)$ & $30(66.67)$ & 2.42 & 0.298 & 0.6 & $0.19-2.26$ \\
\hline Low & $5(11.11)$ & $10(22.22)$ & & & 0.3 & $0.06-1.47$ \\
\hline Not experience & $8(17.78)$ & $5(11.11)$ & & & & \\
\hline \multicolumn{7}{|l|}{ 8-OHdG n (\%) } \\
\hline High & $30(66.67)$ & $13(28.89)$ & 12.86 & 0.000 & 4.9 & $2.01-12.03$ \\
\hline Low & $15(33.33)$ & $32(71.11)$ & & & & \\
\hline
\end{tabular}

Table 3: Multivariate Analysis of Nutrient Intake, Mental Status and 8-OHdG Urine Levels with PMS

\begin{tabular}{|c|c|c|}
\hline Variables & & \\
\hline & 1 & 2 \\
\hline
\end{tabular}

Fat

More

$(0.75-8.03)$

$(0.43-5.81)$

$(0.37-5.36)$

1.23
1.5

(0.26-4.26)

Less

2.1

(o.63-7.33)

1.3

(0.36-5.22)

Reference

1

1

(o.31-4.79)

8-OHdG

High

Low (Reference)

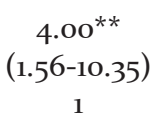

$4.1^{* *}$
$(1.51-11.49)$
1

$3.8^{*}$
$\left(1.33^{-11.13}\right)$

$5.3^{*}$
$(1.50-18.99)$
1

(1.44-19.00)

Stress

High

Medium

$9.0^{* *}$
$(2.09-39.05)$

1.8
$(0.47-7.45)$

1.1

(0.30-4.04)

Not experience (Reference)
$8.0^{* *}$
$(1.80-35 \cdot 97)$
1.7
$(0.42-7.07)$
1.09
$(0.29-4.00)$

1

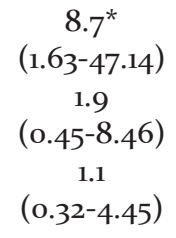

1

0.7

(0.19-2.96)

2.3

(0.59-9.07)

1

$$
0.69
$$$$
\text { (o.14-3.26) }
$$

1

1

$$
9.2^{*}
$$$$
\text { (1.66-51.9) }
$$$$
1.9
$$$$
\text { (0.42-8.44) }
$$$$
1.08
$$$$
\text { (o.27-9.32) }
$$

1

0.7

(o.18-3.08)

$$
2.26
$$

(0.54-9.32)

Not experience (Referenc)

\section{Calcium}

Less

Reference

$$
\begin{gathered}
1.4 \\
\text { (0.30-6.91) }
\end{gathered}
$$




\section{Table 3: (Continued)}

\begin{tabular}{|c|c|c|c|c|c|}
\hline \multirow[t]{2}{*}{ Variables } & \multicolumn{5}{|c|}{ Models } \\
\hline & 1 & 2 & 3 & 4 & 5 \\
\hline \multicolumn{6}{|l|}{ Zinc } \\
\hline Less & & & & & $\begin{array}{c}2.2 \\
\text { (0.58-8.19) }\end{array}$ \\
\hline Reference & & & & & 1 \\
\hline $\mathrm{R} 2 \%$ & 12.5 & 20.8 & 21.2 & 23.2 & 25.2 \\
\hline Deviance & $2975 \cdot 7$ & 2437.3 & 2411.7 & 2291.5 & 2175.2 \\
\hline $\mathrm{N}$ & 90 & 90 & 90 & 90 & 90 \\
\hline
\end{tabular}

* = significant, $p$-value $<0.05$

$* *$ significant, $p$-value $<0.01$

The result of the analysis showed that intake of fat, lack of calcium and zinc, stress, depression, and high levels of urine 8-OHdG had a statistically significant relationship with the incidence of PMS. P-values for fat, calcium, zinc, and depression were $<0.05$, while stress and urine $8-\mathrm{OHdG}$ were $<0.01$ (Table 2).

Fat, calcium, zinc, stress, depression, and urine $8-\mathrm{OHdG}$ in model 5 can predict the incidence of PMS by $25.2 \%$ (R2= 0.252). From the results of the analysis with several models, researchers tend to choose model 2 as a predictor of PMS events, that is urine $8-\mathrm{OHdG}$ levels and stress as models that are more effective and efficient, statistically and practically meaningful, which affect the incidence of PMS. Urine 8-OHdG levels and stress can predict the incidence of PMS by $20.8 \%(\mathrm{p}<0.01 ; \mathrm{R} 2=0.208)$ (Table 3$)$.

\section{DISCUSSION}

The prevalence of PMS is $28.9 \%$. Intake of fat, calcium, zinc, stress, depression, and urine 8-OHdG levels was significantly associated with the incidence of PMS $(p<0.05$ and $p<0.01$ ). These results are in line with previous studies where excess fat can cause PMS. ${ }^{2,8}$ Carbohydrates, protein, and vitamin D are not associated with the incidence of PMS. Less fat intake is also at high risk for PMS. In theory, fat (cholesterol) is the basic ingredient of the formation of steroid hormones. Progestins, androgens, and estrogens can be synthesized in situ in various ovarian tissues with cholesterol as a common steroid precursor. ${ }^{17}$ PMS occurs as one of the effects of the imbalance of the hormones estrogen and progesterone. So that excess or lack of fat intake can affect the stability of hormone levels in the body. Fat is also related to adipose tissue which will affect body mass index (BMI). However, this study did not measure BMI in adolescents. BMI is associated with the incidence of PMS, so that despite a lack of fat intake, on the other hand, there are risk factors such as BMI that can contribute to causing PMS. ${ }^{11,12}$
Lack of calcium and zinc intake are also at risk for PMS. The average calcium intake of adolescents is only 486.30 $\mathrm{mg}$ from the standard $1.200 \mathrm{mg} /$ day. Calcium plays an important role in the synthesis of neurotransmitters (serotonin) and affects mood symptoms and emotional irregularities in PMS. ${ }^{9}$ The recommended standard of zinc requirement for adolescents is $16 \mathrm{mg} /$ day (ages 13-15 years) and $14 \mathrm{mg} /$ day (16-18 years) while the average intake of adolescent zinc in this study is $9.54 \mathrm{mg} /$ day. Zinc deficiency can increase the risk of depression ${ }^{10}$ and anxiety which are symptoms of PMS through decreased levels of gamma-aminobutyric acid (GABA) ${ }^{11}$ Higher TAC (Total Antioxidant Capacity) and zinc serum are also associated with a reduced risk of experiencing $\mathrm{PMS}^{18}$. Although not significantly related, in theory, the amount of vitamin D in the body affects the absorption of calcium where the absorption process will not take place properly without the support of adequate vitamin D. Besides that, other factors influence the incidence of PMS, namely an increase in inflammatory cytokines. Vitamin D in this case can act as an anti-inflammatory metabolite that may affect some of the symptoms of PMS.

Stress is related to PMS events. Adolescents with severe stress are 10.1 times more at risk of experiencing PMS than those without stress. Risk increases with stress levels. This finding is in line with studies in which women with moderate and severe stress were 2.49 and 4.9 times at risk for PMS. ${ }^{3}$ Adolescence is a dramatic change in the functioning of the Hypothalamic Pituitary Axis (HPA), the stress response, is also a significant period of sustained nerve maturation, especially in stress-sensitive cortical and limbic areas. Prolonged or repeated stress exposure results in a higher sensitivity to this stressor, which in turn leads to maladaptive neurobehavioral development ${ }^{19}$. Stress causes mood changes through the decreased beta-endorphin brain and increased adrenal cortisol. The effect of cortisol causes hormonal imbalances and creates psychological symptoms and mood changes which are symptoms of PMS. ${ }^{16-18}$ 
Anxiety does not indicate any association with PMS. As for adolescents who experience depression are also at risk of experiencing PMS. This can be caused by a lack of calcium and zinc intake in the adolescent. Subjects who are depressed show high susceptibility to the sympathetic nerves and this condition in response to stress. Increased ROS (Reactive Oxygen Species) by activation of the sympathetic nervous system causes oxidative damage to DNA. Depression was found to be related to increased oxidative stress and decreased antioxidant status. It is possible that women who are depressed can make a lifestyle that triggers an increase in oxidative stress, the presence of fluctuations from estradiol and FSH (follicle-stimulating hormone) associated with depressive symptoms that can increase oxidative stress, and finally, oxidative stress can reduce serotonin and norepinephrine levels that lead to depressive symptoms. ${ }^{14,20}$

Adolescents with high levels of $8-\mathrm{OHdG}$ in urine are also at risk for PMS. High levels of 8-OHdG can be caused by high fat intake, lack of calcium and zinc, stress, and depression in adolescents. 8-OHdG levels tend to increase during the proliferation phase. On the other hand, $20-50 \%$ of women complain of depression, anxiety, and fatigue 7-10 days before menstruation which is one of the symptoms of $\mathrm{PMS}^{15}$. Increased oxidative stress and decreased antioxidant capacity can occur in PMS, and an imbalance from the oxidant/ antioxidant system can also be a cause or effect of various types of stress symptoms that occur in PMS. ${ }^{6}$

Stress and 8-OHdG urine levels are predictors of PMS events in this study. In line with the findings ${ }^{13}$ stress is the strongest predictor of the severity of PMS symptoms, while physical exercise and nutritional intake are not related to PMS. This finding is reinforced by other studies where the intensity of PMS is associated with an increase in psychological predictors namely depression, anxiety, stress, and poor sleep quality. ${ }^{12,18-20}$

Characteristics of respondents who are teenagers and high school students with dense intracurricular and extracurricular activities so that they are vulnerable to stress. Psychological stress ahead of school exams also increases the production of ROS and oxidative stress, thereby causing damage to biomolecules that continue to damage cells and tissues. This condition is characterized by increased levels of $8-\mathrm{OHdG}$ in urine. ${ }^{15}$ Increased oxidative stress and decreased antioxidant capacity can occur during PMS. This indicates an antioxidant imbalance before menstruation and can be related to the pathogenesis of PMS. ${ }^{6,7}$

\section{CONCLUSION}

Intake of fat, calcium, zinc, stress, depression, and levels of 8-OHdG in urine can affect the occurrence of PMS in adolescents. Stress and 8-OHdG levels in urine can be a pre- dictor of PMS. A special counselling group for adolescent reproductive health is needed and education about the importance of antioxidant-rich nutrients in counteracting oxidative stress. Further research on oxidative stress can be carried out to better understand its role in the incidence of Premenstrual Syndrome (PMS).

\section{ACKNOWLEDGMENT}

Authors acknowledge the immense help received from the scholars whose articles are cited and included in references to this manuscript. The authors are also grateful to authors / editors / publishers of all those articles, journals, and books from which the literature for this article has been reviewed and discussed.

\section{Conflict of Interest: Nil}

\section{Source of Funding: Nil}

\section{REFERENCES}

1. Mohebbi M, Amir S, Akbari A, Mahmodi Z, Nasiri M. Comparison between The Lifestyle of University Students with and without Premenstrual Syndromes. Electron Physician. 2017;9(6):4489-96.

2. Hashim MS, Obaideen AA, Jahrami HA, Radwan H, Hamad HJ, Owais AA, et al. Premenstrual Syndrome is Associated with Dietary and Lifestyle Behaviors among University Students. Nutrients 2019;11(1939):1-18.

3. Fernandez MDM, Mendez CR, Takkouche B. Psychological Factors and Premenstrual Syndrome : A Spanish Case-control Study. PLoS One 2019;14(3):1-13.

4. Amiel Castro RT, Pataky EA, Ehlert U. Associations between premenstrual syndrome and postpartum depression : A systematic literature review. Biol Psychol 2019 Oct;147:107612.

5. Roomruangwong C, Kanchanatawan B, Sirivichayakul S, Mahieu B, Nowak G, Maes M. Lower Serum Zinc and Higher CRP Strongly Predict Prenatal Depression and Physio-somatic Symptoms, Which All Together Predict Postnatal Depressive Symptoms. Mol Neurobiol 2017;54:1500-12.

6. Duvan CI, Cumaoglu A, Turhan NO, Karasu C, Kafali H. Oxidant/antioxidant Status in Premenstrual Syndrome Oxidant/antioxidant Status in Premenstrual Syndrome. Arch Gynecol Obs. 2011;283:299-304.

7. Al-Gubhory KH, Ismail L, editors. Nutritional Antioxidant Therapies : Treatments and Perspectives. Springer International Publishing; 2017.

8. Vani RK, Veena K, Subitha L, Hemanth Kumar V, Bupathy A. Menstrual Abnormalities in School Going Girls - Are They Related to Dietary and Exercise Pattern? J Clin Diagnostic Res 2013; 7(11):2537-40.

9. Hollins-Martin C, Akker O van den, Martin C, Preedy VR, editors. Handbook of Diet and Nutrition in The Menstrual Cycle, Periconception and Fertility. 7th ed. Wagenigen Academic Publishers; 2014. Pg 95.

10. Wang J, Um P, Dickerman BA, Liu J. Zinc , Magnesium, Selenium and Depression: A Review of the Evidence, Potential Mechanisms and Implications. Nutrients 2018;10(584):1-19. 
11. Russo AJ. Decreased Zinc and Increased Copper in Individuals with Anxiety. Nutr Metab Insights 2011;4:1-5.

12. Prabhavathi K, Thilip Kumar G, Hemamalini R V, Poornima K N, Saravanan A Study of psychological predictors and sleep quality in different grades of premenstrual syndrome. Natl $\mathrm{J}$ Physiol Pharm Pharmacol. 2018;8(3).

13. Walton LM, Machamer L, Asumbrado R, Behrens MA. Physiotherapy \& Physical Rehabilitation Relationship between Nutrition (REAP), Exercise (VSAQ), and Stress on Premenstrual Syndrome Severity (PSST): Correlation, Cross-Section, Purposive Sample of 75 Females Ages 18-55. J Physiother Phys Rehabil. 2018;3(2):1-6.

14. Iida $\mathrm{T}$, Inoue $\mathrm{K}$, Ito $\mathrm{Y}$, Ishikawa $\mathrm{H}$, Kagiono $\mathrm{M}$, Teradaira $\mathrm{R}$, et al. Comparison of Urinary Levels of 8-Hydroxy-2'-deoxyguanosine between Young Females with and without Depressive Symptoms during Different Menstrual Phases. Acta Med Okayama 2015;69(1):45-50.

15. Iida T, Ito $Y$, Ishikawa $H$, Kanazashi M, Teradaira R. Effects of Psychological Stress from a National License Examination on the Urine 8-Hydroxy-Deoxyguanosine Levels in Young Female Students , Taking into Account the Menstrual Cycle. Open J Prev Med 2018;8:21-31.
16. Zanolin ME, Girardi P, Degan P, Rava M, Olivieri M, Gennaro G Di, et al. Measurement of a Urinary Marker (8-hydroxydeoxy guanosine, 8-OHdG) of DNA Oxidative Stress in Epidemiological Surveys: a Pilot Study. Int J Biol Markers 2015;30(3):341-5.

17. Fritz MA, Speroff L. Clinical Gynecologic Endocrinology and Infertility. 8th ed. Philadelphia: Lippincott Williams and Wilkins; 2011.

18. Fathizadeh S, Amani R, Haghighizadeh MH, Hormozi R. Comparison of Serum Zinc Concentrations and Body Antioxidant Status between Young Women with Premenstrual Syndrome and Normal Controls : A Case-control Study. Int J Reprod Biomed 2016;14(11):699-704.

19. Romeo RD. The Teenage Brain: The Stress Response and the Adolescent Brain. Curr Dir Psychol Sci 2014;22(2):140-5.

20. Hirose A, Terauchi M, Akiyoshi M, Owa Y, Kato K, Kubota T. Depressive Symptoms are Associated with Oxidative Stress in Middle-aged Women : a Cross-sectional Study. Biopsychosoc Med 2016;10(12):1-6. 